\title{
Converting an automobile turbocharger into a micro gas turbine
}

\author{
M Usman Butt \\ Mechanical Engineering Dept, University of Lahore, 1-km raiwind road, Lahore, Pakistan
}

\begin{abstract}
A low cost micro turbojet made by using an automobile turbocharger and other automobile components for research is presented in this paper. The machine comprises mainly of three main assemblies, the compressor \& turbine assembly, the combustion chamber and the lubrication \& cooling accessories. Carefully selected turbocharger with correct compressor \& turbine combination by taking into account their efficiencies and losses associated with their small size and suitably designed combustion chamber results in a self-sustaining turbojet. The combustion chamber is composed of a combustion liner/flame tube and an outer cylinder. The flame tube is divided into three different zones to allow complete combustion and cooling of hot gases. The fuel used is liquid petroleum gas (LPG). The maximum pressure recorded in the combustion chamber was 11.5 psi and a pressure loss of about $4 \%$. The maximum rpm (revolutions per minute) of the engine ranged to 84000 .
\end{abstract}

\section{Introduction}

Invention of jet engines had revolutionized the air travel. Aircrafts could achieve speeds greater than the speed of sound using these engines. Military and commercial jet engines (even the small ones) are however extremely expensive and complex. Micro turbines are small, easy to operate but their efficiencies are too low especially in case of radial turbines. To increase the efficiency of microturbines a significant amount of research needs to be done on individual component efficiencies, pressure ratio as well as turbine inlet temperature. The basic principle of a micro turbojet is the same as of a traditional Jet engine which is that the air is compressed by the compressor and sent to the combustion chamber. The air is mixed with the fuel in the combustion chamber and ignited. The immense heat produced by the exothermic reaction expand the gases present in the combustion chamber and rushes them to the turbine. As the turbine is connected to the compressor it turns the compressor to complete the cycle. The gases leaving the turbine still have some energy. This energy is either converted into thrust (as in case of current machine) by using a converging duct or into mechanical energy using a secondary turbine. Scaling down the Gas turbines components has however dramatic effects on their efficiencies, resulting in extremely poor cycle efficiencies or sometimes even nonstarter. Several attempts [1] have been made to develop microturbines with efficiency levels comparable to those of larger Gas turbines. The major technical challenges in achieving desired performance are the small scale effects:

- High viscous losses due to low Reynolds numbers in the flow passages of turbo machinery

- $\quad$ High tip clearences
- Lower component efficiencies (i.e. compressor $\&$ turbine)

- Large area to volume ratios causing high heat losses

- Losses in auxillary systems

A gas turbine uses the same concept to produce power. The turbo machinery dimensions for power levels lower than $10 \mathrm{~kW}$ become very small. A $3 \mathrm{kw}$ rated gas turbine would require a radial compressor of diameter ranging from 30 to $40 \mathrm{~mm}$ according to Baljie [2]. It must run at a speed of 100,000 rpm.

A major factor is cost. Development of efficient micro turbines is very expensive due to the above mentioned loses associated with the size of the components. Using an automobile turbocharger is an amazing opportunity to solve the cost problem. Small turbocharger s have become sufficiently efficient in the recent years to sustain Gas turbine cycles and are available at low cost due their abundance in the market. Some studies [1] have shown that $16 \%$ thermal efficiency can be achieved for a turbocharger based micro turbine having a recuperator. Without a recuperator the efficiency drops down to about one-half.

\section{Application}

Main focus of the current project is to develop small, cost effective turbojet for applications including prime movers for auxiliary power units (APU), ground power units (GPU), micro propulsion systems and other specialized applications in aviation for research on thermal and mechanical efficiencies. Once the efficiencies are configured and enhanced to commercially viable levels the program can be extended 
to develop microturbines for combined heat and Power applications at remote places. The major attention is given to cost, reliability, low maintenance and easy operation

\section{Basic design}

As already mentioned, the turbocharger which resembles a Gas turbine in many ways offer a great opportunity to develop low cost micro-turbines. The compressor and turbine can be selected and matched without much modification. By adding a combustor, fuel system and control unit, a simple turbojet engine can be built.

Laboratory tests have shown that turbine inlet temperatures up to $1000^{\circ} \mathrm{C}$ are feasible with the customary Inconel 713 material [3]. With advanced materials such as MAR-M247 TIT can be raised up to $1050^{\circ} \mathrm{C}$ [4]. With these TIT levels for a small turbocharger-based microturbine rated at 200-250 g/s air flow, a thrust output of $150 \mathrm{~N}$ or a power output of 10$12 \mathrm{~kW}$ is achievable.

Schematic of a simple turbojet utilizing an automobile turbocharger is shown in Fig. 1. Its capability of spinning at several thousand rpms and withstanding immense heat and low cost due to large production volumes makes it ideal for conversion into a micro turbojet/gas turbine. The combustion chamber can be designed for a range of liquid/gaseous fuels. However the one described in this article is for liquid petroleum gas (LPG) which is easily available.

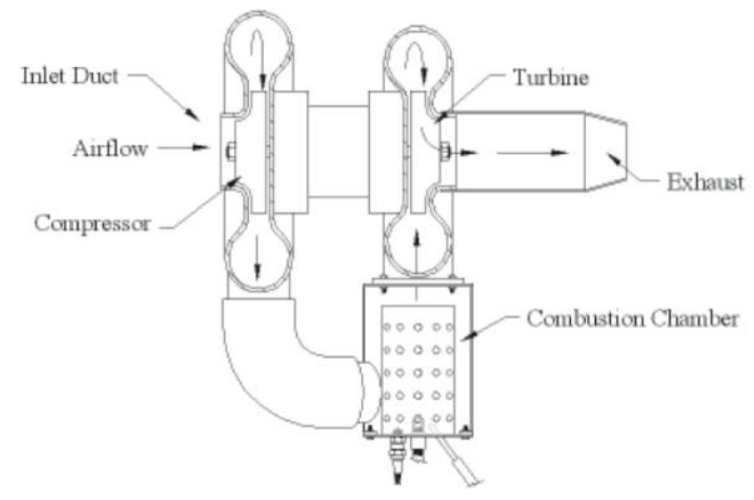

Fig. 1. Schematic of turbocharger Gas turbine

\subsection{Compressor and turbine efficiencies and losses}

A significant improvement has been witnessed in modern small turbocharger turbomachinery performance over the last decades. Although small in size compressors with isentropic efficiencies of $75 \%$ and turbines with efficiencies greater than $65 \%$ are available. They can further be improved or optimized for use in micro gas turbines.

- As the turbochargers in automobile operate at a variety of flows, their impeller and diffuser are accordingly optimized [5]. For gas turbine application they are adapted where pressure ratio and efficiency are at their peak.
- The turbines are designed to have maximum efficiency at lower pressure ratios for automotives [6]. They can however be used for maximum possible efficiency with higher pressure ratios. Nozzle guide vanes will not bring any positive change in efficiency $[7,8]$

Compressor turbine matching was performed for the present micro turbine. Generally compressors are larger than the turbines in small turbochargers. For a micro turbine of this size to sustain larger turbine is needed to adjust to the inlet condition. Present turbine is $22 \%$ larger in diameter than the compressor.

\subsection{Selection of Turbocharger}

A micro turbine cycle requires higher design inlet temperature and hence a larger turbine. On the other hand the customary combinations of compressors and turbines for the automobile application are far from optimal for the micro turbine application. Therefore, a turbo machinery selection study has been carried out for optimal matching of turbocharger compressor and turbine. Publicly available component performance maps from the world's leading manufacturers have been assessed to find the optimal compressor turbine match for the proposed Gas turbine cycle.

Fig. 2 shows a HINO 7C compressor with the housing removed. The turbine is about $8 \mathrm{~mm}$ larger than the compressor.

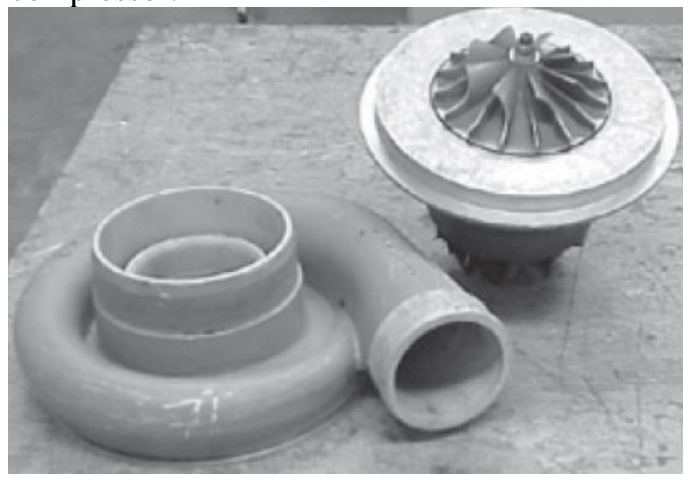

Fig. 2. Turbocharger from HINO 7C

\section{Engine Design}

The matching of components and market search resulted in a turbocharger having an inducer size of $53 \mathrm{~mm}$ for compressor (Fig. 3). The turbine exhaust diameter (exducer) is $61 \mathrm{~mm}$.

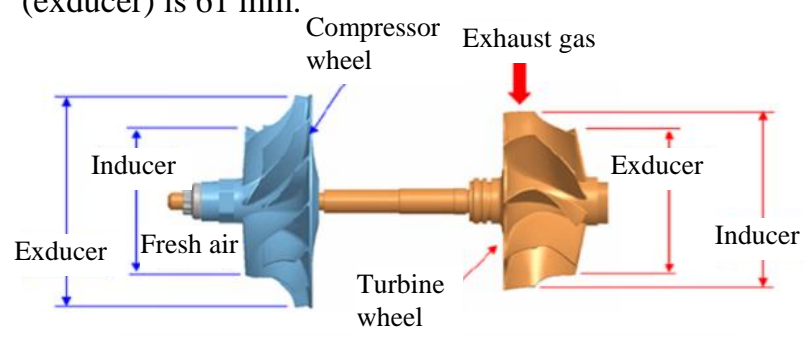

Fig 3. Basic geometry \& terminology of turbo components 
Use italics for variables $(u)$ and bold (u) for vectors. The order for brackets should be $\{[()]\}$, except where brackets have special significance.

The design point of the gas turbine is chosen to be at $70 \%$ compressor efficiency, PR of 2.1 and an rpm of 104,000 on the compressor map. These magnitudes lie within the measurement ranges of available measuring equipment. Hence this point is good choice to later observe and compare the measured engine performance with the designed one.

The temperature of air after being compressed at $70 \%$ efficiency will be $391 \mathrm{~K}$. The power required to spin the compressor to produce this $\mathrm{PR}$ and temperature rise is $24 \mathrm{~kW}$. This must be the minimum power produced by the turbine along with a bit more for bearing friction. Using this and the specific heat capacities $(\mathrm{Cp})$ of hot gases the temperature drop across the turbine is estimated to be around $90 \mathrm{~K}$. The corresponding pressure drop across the turbine running at an isentropic efficiency of $60 \%$ will be 1.7 . Now a pressure ratio of about 1.23 will be available for making thrust. A thrust well above $90 \mathrm{~N}$ can be produced with the available mass flow rate and using an ideal converging nozzle

\subsection{Combustion Chamber}

The combustor must be designed for minimum possible pressure loss due to low pressure ratios associated with the cycle. Common engineering methods $[9,10,11]$ as well as experienced values ere extensively used to design the combustor The combustion liner/flame tube is divided into three areas, the primary, secondary and tertiary (Fig. 4). Combustion takes place in primary and secondary section. The holes having an area equivalent to $20 \%$ of the compressor inducer are drilled at this stage. It is here where the primary combustion takes place. The incoming air in this stage is given a little swirl by tapering the holes to insure an efficient mixing of the fuel and air. $30 \%$ of the air is used to complete the combustion in the second stage. The temperature of the flame rise well above $1200^{\circ} \mathrm{C}$ and must be cooled down before entering the turbine section. The rest of the air (50\%) coming from the compressor is used for cooling the hot gases through tertiary holes. The liner area was determined as a compromise between combustion stability and jet penetration. The liner volume was defined for a combustion intensity of $60 \mathrm{MW} / \mathrm{atm} \mathrm{m}^{3}$

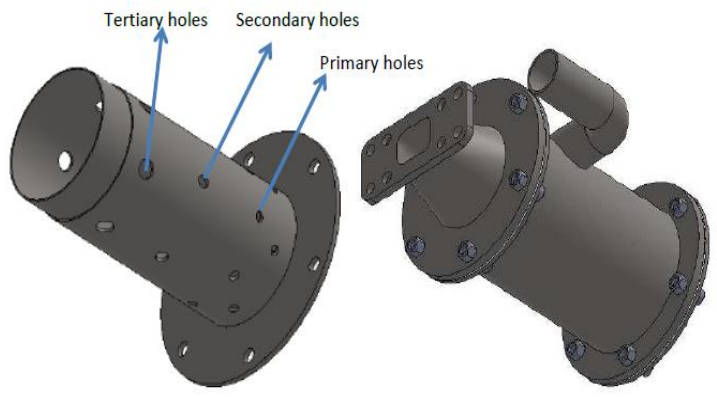

Fig. 3. Flame tube (a) \& complete combustion chamber (b)
Flame tube serves two purposes. First it keeps the outer chamber cool and secondly it provides three zones for complete combustion.

Fuel is injected using an in-house built fuel nozzle. Fuel Nozzle is a $6 \mathrm{~mm}$ steel tube with six $1 \mathrm{~mm}$ holes drilled along the circumference. The size and number of holes were chosen after numerous tests with various hole dimensions as to ensure that the fuel (LPG) is coming with enough force to efficiently mix with the incoming air.

\subsection{Converging Nozzle}

The exhaust gases leaving the turbine still possess enough energy which can be used either to create thrust or drive another turbine to generate power. The available pressure at the turbine exhaust was about 3.5 psi. A converging nozzle is mounted to accelerate the exhaust gases and produce thrust (Fig. 5).

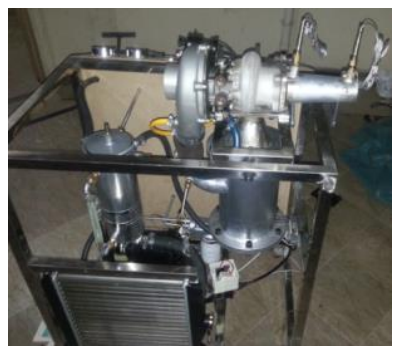

Fig. 5.Complete engine setup

\section{Test Results \& Discussion}

Following quantities were measured at different locations to observe the performance of the engine.

- $\quad$ pressures at all stations

- temperatures at all stations

- $\quad$ rotational speed using fiber optic sensor

- $\quad$ oil pressure and temperature

- heat exchanger inlet/exit temperatures

- fuel pressure

A brief summary of the engine performance is shown in Table 1. This include pressure and temperature of the compressed air, rotational speeds, exhaust gas temperatures etc. The pressure of the compressed air (Boost pressure) entering the combustion chamber was measured using Bourdon gauge having measurement range of 30 psi. It showed a maximum of $11.5 \mathrm{psi}$ at an rpm of 84,000 .

Table 1. Performance chart of the engine (measured)

$\begin{array}{lll}\begin{array}{l}\mathbf{T}_{\mathbf{0}} \text { (Ambient } \\ \text { Temperature) }\end{array} & 293 & \mathrm{~K} \\ \text { P }_{\mathbf{0}} \text { (Ambient Pressure) } & 1 & \mathrm{bar} \\ \mathbf{T}_{\mathbf{c}} \text { (Combustor inlet } & 365 & \mathrm{~K} \\ \text { Temp) } & & \\ \begin{array}{l}\text { PR (Pressure ratio) } \\ \text { N (rotations) }\end{array} & 1.75 & \text { Revolutions per } \\ & 84000 & \text { minute } \\ \text { Eta (cycle efficiency) } & 6 & \mathrm{~K} \\ \text { TIT (Turbine Inlet } & 1073 & \\ \text { Temp) } & & \end{array}$




$\begin{array}{lll}\text { T (Thrust) } & 75 & \mathrm{~N} \\ \mathbf{T}_{4} \text { (Turbine outlet } & 975 & \mathrm{~K} \\ \text { Temp) } & & \\ \mathbf{T}_{5} \text { (Exhaust Temp) } & 919 & \mathrm{~K} \\ \mathbf{P}_{\mathrm{f}} \text { (Fuel Pressure) } & 5 & \mathrm{bar}\end{array}$

The rpm were measured with the help of Omron optical sensor connected with the display through two fiber optic cables. The measurement range is $0-99,000$. The sensor emitting laser beam was placed near the hub of the compressor shaft at a distance of about $5 \mathrm{~mm}$ in radial position. The shaft hub was painted half black and half white to enable clear reflections. Minimum speed required to keep the engine self-sustaining is $30,000 \mathrm{rpm}$. Maximum speed achieved by the turbine ranged to around 84,000 rpms.

The temperature of the compressed air (Combustor inlet) was measured with the help of K-type thermocouple connected to temperature controller from Omega having a measuring range of $0-1300^{\circ} \mathrm{C}$. The maximum temperature at the highest rpm obtained was $92^{\circ} \mathrm{C}$. The exhaust temperature was measured using similar thermocouples and ranged from $550^{\circ} \mathrm{C}$ to $650^{\circ} \mathrm{C}$ depending on the engine rpms.

From the test analysis, compressor efficiency could be determined: at $70 \%$ and turbine efficiency at $60 \%$ at highest rotational speeds which corresponds the design values. The produced thrust is about $75 \mathrm{~N}$ which less than the calculated thrust in the previous section caused by the losses in the converging nozzle. The thrust was measured using a load cell having a measurement range of 0-300 N. The thermal efficiency of the engine at present pressure ratio lies around $6 \%$. About $70 \%$ of the combustion power is used by the turbine to run the compressor and work against bearing friction. The rest $30 \%$ remains available at Nozzle inlet.

The measured performance of the engine is in close agreement with the calculated one although the max speed of 104000 could not be achieved. The working point lies a little beneath the design point on the compressor map. However the measured rpm, pressure ratio and efficiencies are in perfect match with each other according to the map. Probably a more efficient fuel nozzle and an increased fuel flow rate would be required to further increase the rotational speed and shift the working point of the engine closer to the design point

\section{Conclusions}

Above presented experiments have proven that the turbocharger technology has the potential to develop cost effective micro gas turbines or turbojets. Present turbojet generated a maximum thrust of $75 \mathrm{~N}$. The size of the combustion chamber however needs to be optimized and pressure loss reduced. It would generate electrical power up to $10 \mathrm{~kW}$ if coupled to a generator through a gearbox. Current efficiency of the cycle is not more than $6 \%$. However further developments are on the way i.e. adding a recuperator to enhance the cycle efficiency

\section{References}

1. W. P. J. Visser, S. A. Shakariyants, M. Oostveen, ,Development of a $3 \mathrm{~kW}$ Microturbine for CHP Applications'Journal of Engineering for Gas Turbines and Power, 2011, Vol. 133,

2. Balje, O. E., 1981, "Turbomachines: A Guide to Design," Selection and Theory, Wiley, New York.

3. Tetsui, T., Kyoya, M., and Miura, Y., 2000, "Development of a TiAl Turbocharger for Passenger Vehicles," Mitsubishi Heavy Industries Technical Review, Vol. 37.

4. https://www.turbobygarrett.com/turbobygarrett/ turbochargers/gt2860rs. (accessed on 05/01/2018)

5. Matsumoto, K., Tojo, M., Jinnai, Y., Hayashi, N., and Ibaraki, S., 2008, "Development of Compact and High-Performance Turbocharger for 1,050C Exhaust Gas," Mitsubishi Heavy Industries Technical Review, Vol. 45.

6. 2009, "Super MWE," Holset HTi Magazine, www.holset.co.uk, pp. 7-8.

7. Ryder, O., 2009, "The Worldwide Efficiency Drive," Cummins/Holset Hti Magazine, www.holset.co.uk, pp. 5-6.

8. Spence, S. W. T., Rosborough, R. S. E., Artt, D., and McCullough, G., 2007,

9. "A Direct Performance Comparison of Vaned and vaneless stators for Radial Turbines," ASME J. Turbomach., 129, pp. 53-61.

10. Simpson, A. T., Spence, S. W. T., and Watterson, J. K., 2009, "A Comparison of the Flow Structures and Losses Within Vaned and Vaneless Stators for Radial Turbines," ASME J. Turbomach., 131, p. 031010.

11. Lefebvre, A. H., 1999, Gas Turbine Combustion, Taylor\&Francis, London 